\title{
Your contribution to Gynecological Surgery now freely available to the global scientific community
}

\author{
Jan Deprest ${ }^{*}$, Frederic Amant, Jan Bosteels, Stephan Gordts, Thierry Van den Bosch, Steven Weyers, Sara Brucker, \\ Grigoris Grimbizis, Benoit Rabischong, Attilio Di Spiezio Sardo, Michelle Nisolle, Giovanni Scambia, \\ Ertan Saridogan and Rudi Leon De Wilde
}

\section{Open access to full content}

On May 1 2017, Gynecological Surgery, [1] the official journal of the European Society for Gynaecological Endoscopy (ESGE) [2] and its affiliated societies, has transferred to BioMed Central's [3] open access publishing platform. This eagerly awaited event is the result of a joint decision between the Editorial Board of the journal and the Executive Board of the ESGE made during the 2016 annual congress. Presently, the first open access articles [4] are available to read online, with one particular highlight being a joint publication between ESGE and AAGL [5], signifying how swiftly the global scientific community can freely access the full content of the articles; as will be the case for any future work to be published.

\section{We want your work to be visible for the global scientific community}

Until now, only ESGE members had direct, free access to articles published in Gynecological Surgery. However, now that the transition to an open access publishing platform is complete, both current and back content of the journal will be freely accessible to all readers. This is a pivotal point for the ESGE, its members, and the journal, as research published in Gynecological Surgery will now be visible to the wider scientific community, and eventually will be cited.

This is but a first step for our journal's next ambition, of having its entire content indexed in PubMed, and will also assist in realizing its second goal of obtaining an official impact factor. Receiving an Impact Factor is the end product of a complex and balanced interplay between the submission of valuable, relevant content to the

\footnotetext{
* Correspondence: Jan.Deprest@uzleuven.be

Department of Obstetrics and Gynaecology, Universitaire Ziekenhuizen Leuven, Leuven, Belgium
}

community (the numerator), and stringent limitations in acceptance rates to keep the denominator low. The Editors of Gynecological Surgery have been implementing this policy since the journal's launch, quadrupling its theoretical Impact Factor over the past five years. This rigorous peer-review process will stay in place in order to offer publications of a high standard, while also aiming to increase citations and improve the journal's chances of receiving an official Impact Factor.

\section{New Associate Editors will speed up the review process}

In the months to come, the ESGE will recruit up to 15 Associate Editors who will oversee and participate in the peer review process. We are increasing the number of editors to shorten the review procedure, as it lowers the load per handling editor. Associate Editors will assign candidate reviewers and, when needed, chase them to complete their review within three weeks after their acceptance of the invitation. Associate Editors will take pre-emptive action and assist in the review process so that it can be completed within 30 days after assignment to an Associate Editor.

\section{Initial advantages for ESGE members: publication free of charge}

Submitting your research to Gynecological Surgery [6] takes advantage of its efficient online submission system, swift, high-quality peer-review service, and publication shortly after acceptance. As a fully open access title, all articles from Gynecological Surgery are freely accessible as full text, making your research visible to the widest possible global audience. The journal complies with the open access policies [7] of many funders including those of the Howard Hughes Medical Institute [8], NIH [9], and Wellcome Trust [10]. 
To enable the journal to make all of its future content open access, Gynecological Surgery now levies an article processing charge (APC) [11] payable upon editorial acceptance. However, for members of the ESGE, the APC will be covered by the Society for up to 36 articles during 2017. In the next few years, the Society will continue to sponsor its members by paying the APC, with the number of sponsored manuscripts to be determined on a yearly basis.

Please note also that if the submitting author's organization is a BioMed Central member [12], the cost of the APC is covered in full or in part by the membership. Additionally, there are no color charges on figures or embedded movies.

Yours sincerely,

Jan Deprest (EiC), on behalf of Frederic Amant, Jan Bosteels, Stephan Gordts, Thierry Van den Bosch, and Steven Weyers, Editors of Gynecological Surgery, and

Grigoris Grimbizis, on behalf of the Board of ESGE, including Rudi Leon De Wilde, Sara Brucker, Benoit Rabischong, Attilio Di Spiezio Sardo, Michelle Nisolle, Giovanni Scambia ESGE Executive Board Member Ertan Saridogan Co-opted ESGE Executive Board Member

Authors' contributions

All authors read and approved the final manuscript.

\section{Competing interests}

The authors declare that they have no competing interests.

Received: 23 May 2017 Accepted: 29 May 2017

Published online: 02 August 2017

\section{References}

1. Gynecological Surgery. http://www.gynecolsurg.springeropen.com

2. European Society for Gynaecological Endoscopy (ESGE). http://www.esge. org

3. BioMed Central. https://www.biomedcentral.com/

4. Gynecological Surgery. https://gynecolsurg.springeropen.com/articles

5. AAGL practice report: practice guidelines on intrauterine adhesions developed in collaboration with the European Society of Gynaecological Endoscopy (ESGE). Gynecological Surgery. 2017;14(1):6

6. Editorial Manager. https://www.editorialmanager.com/gyns/default.aspx

7. BioMed Central, about open access. https://www.biomedcentral.com/about/ open-access

8. Howard Hughes Medical Institute. http://www.hhmi.org/

9. National Institutes of Health. https://www.nih.gov/

10. Wellcome Trust. https://wellcome.ac.uk/

11. BioMed Central's article-processing charges. https://www.biomedcentral. com/getpublished/article-processing-charges

12. BioMed Central Institutional support. https://www.biomedcentral.com/ about/institutional-support/membership

\section{Submit your manuscript to a SpringerOpen ${ }^{\circ}$ journal and benefit from:}

- Convenient online submission

- Rigorous peer review

- Open access: articles freely available online

- High visibility within the field

Retaining the copyright to your article

Submit your next manuscript at $\boldsymbol{s p r i n g e r o p e n . c o m ~}$ 